\title{
Effects of Electrokinetics on Arsenic Mobility and Accumulation in Mott Dwarf Napier Grass for Treatment of Mine Tailings
}

\section{Kitsadee Wanitsawatwichai}

Chulalongkorn University

Pantawat Sampanpanish ( $\sim$ pantawat.s@chula.ac.th )

Chulalongkorn University https://orcid.org/0000-0002-2561-7459

\section{Research}

Keywords: Arsenic, Electrokinetic, Mott Dwarf Napier Grass, Mine Tailings, Phytoremediation

Posted Date: July 25th, 2020

DOI: https://doi.org/10.21203/rs.3.rs-27925/v2

License: (c) (i) This work is licensed under a Creative Commons Attribution 4.0 International License.

Read Full License 
The authors have withdrawn this preprint from Research Square 